\title{
GESTO SOBRE UM POEMA DE HILDA HILST EM FRANCÊS
}

\author{
Álvaro Faleiros
}

\begin{abstract}
Alguns horizontes da tradução poética na França
Difícil pensar na tradução de literatura para o francês hoje sem considerar as reflexões de Antoine Berman e de Henri Meschonnic. Teóricos de projeção internacional, ambos destacaram a existência de uma atitude predominantemente etnocêntrica no horizonte tradutório francês.

Berman (2007), em seu ensaio A tradução e a letra ou o albergue do longínquo, publicado originalmente em 1985, é quem mais se debruça sobre o que chama de “tradução etnocêntrica”. Para ele,
\end{abstract}

\begin{abstract}
Esta concepção que gerou na França, nos séculos XVII e XVIII, as “belas infiéis”, pode parecer ultrapassada. Não estamos mais na época em que se transformava, pela própria vontade, uma obra estrangeira. [...] Os tempos mudaram. Ou seja, os critérios morais desapareceram. A abundância de correções, acréscimos, supressões, modificações de qualquer índole diminuiu. Mas nem por isso desapareceu. (Berman, 2007: 29)
\end{abstract}

Um pouco mais à frente, ainda afirma que ser etnocêntrico é, em tradução, trazer tudo para sua própria cultura, normas e valores. O estrangeiro, ou seja, aquilo que se encontra fora da cultura de chegada, serve talvez para ser anexado ou adaptado, quando não é simplesmente considerado negativo.

É nessa perspectiva que Berman identifica um série de tendências deformadoras que, em grande medida, como afirma o próprio autor, tem na "homogeneização" uma espécie de resultante (p. 55). As causas dessa homogeneização são práticas como a adoção de: sintaxe mais direta e simples (racionalização, destruição de sistematismos); explicações, substituições e omissões lexicais (clarificação, alongamento, enobrecimento, empobrecimento quantitativo, exotização ou destruição das redes vernaculares, destruição das locuções, apagamento da superposição de línguas); alterações fonossemânticas e rítmicas (empobrecimento qualitativo, destruição dos ritmos, destruição das redes significantes subjacentes). 
As reflexões de Berman derivam, em certa medida, daquelas de Meschonnic que, por exemplo, ao comentar as traduções de Paul Celan feitas por André du Bouchet, atenta para o fato de que a prática de tradução em questão, pelos seus acréscimos explicativos, omissões de repetições, deslocamentos não necessários da sintaxe, arcaísmos e evicção da palavra simples, entre outros procedimentos, levam a uma "quebra de ritmo"; do qual deriva um "obscurecimento e uma censura que configuram bem a prática, não teórica do traduzir poemas, em francês, hoje, por alguns” (Meschonnic, 1973: 390).

Com efeito, as posturas adotadas pelos dois teóricos têm o objetivo comum de atentar para o fato de que, na França, assim como na maioria das culturas dominantes, tende-se a "homogeneizar” a tradução, ou então “quebrar o ritmo do texto”. Dentre os dois autores, é este último quem se dedica ao texto poético, além de também sistematizar as "tendências deformadoras"; chamadas por ele de "teratologias" (Meschonnic, 1999: 27).

Seriam elas quatro: as supressões ou omissões de palavras ou de grupos de palavras num texto; os acréscimos, visto que a tradução tenderia a explicitar; os deslocamentos de grupos na sentença; e as substituições. De fato, Meschonnic chama estas últimas de não-concordância, quando uma unidade semântica é traduzida por várias; e de anti-concordância quando várias unidades são traduzidas por uma só, procedimentos que desfiguram o que o autor chama de "ritmo semântico".

O ritmo deve aqui ser compreendido como a "organização do movimento da fala na escritura” (p.56), isto é, o modo como o texto significa, levando em conta a historicidade dos discursos. Quanto à tradução do ritmo do poema, dentre as muitas formulações propostas por Meschonnic, numa de suas últimas afirma:

\footnotetext{
Se para traduzir um poema traduz-se forma, não se traduz poema, mas uma representação da poesia, linguística e poeticamente falsa: linguisticamente porque as unidades traduzidas são as da língua; poeticamente porque um poema é outra coisa além de forma e conteúdo. A unidade poética é o poema, e não as unidades linguísticas que ele contém. (Meschonnic, 2007: 30).
}

Ao afirmar a unidade do poema para além da forma e do conteúdo, Meschonnic privilegia as articulações e o movimento do discurso; o que explica em parte o destaque que dá ao grupo de palavras em sua sistemática da deformação. Sua afirmação também nos permite compreender seu conceito de "não-concordância” e "anticoncordância" como conceitos discursivos (culturais) e não puramente linguísticos, historicizando, 
desse modo, as significações que se depreendem das redes fonossemânticas. Entretanto, ao negar conteúdo e forma em nome da unidade do poema, Meschonnic inviabiliza uma análise dos processos em jogo no poema, anulando inclusive o alcance interpretativo de sua própria teratologia. Parece-nos, portanto, mais produtivo, refletir sobre as dinâmicas “deformadoras” articulando-as no todo do poema.

É importante acrescentar que a reflexão de Meschonnic, assim como a de Berman, é pautada por uma ética. Para Meschonnic, a ética do traduzir reside numa ética da linguagem, linguagem que, afirma o autor seguindo os passos de Benveniste, "serve para viver". Assim "pensar" serviria primeiramente para "inventar o pensamento” (Meschonnic, 2007: 21). A ética para ele é “a busca de um sujeito que se esforça para se constituir como sujeito” (p.8) e a ética do traduzir pode ser compreendida como a reorganização do movimento da fala (e, portanto, desse sujeito) na escritura.

Nesse ponto, Berman e Meschonnic divergem, pois, para Berman (2007: 3839), a ética do traduzir reside em não negligenciar o "contrato fundamental que une a tradução a seu original [...] que proíbe ir além da textura do original” (grifos do autor). E logo abaixo indica que o "projeto ético da tradução” é “levar às margens da língua para a qual se traduz a obra estrangeira na sua pura estranheza, sacrificando deliberadamente sua [do tradutor] 'poética' própria” (ibidem). O risco da postura adotada por Berman é desconsiderar uma série de práticas, classificadas por ele de hipertextuais (adaptações, pastiches, paráfrases...), como procedimentos de tradução que podem, em alguns casos, chegar a determinados movimentos da fala gestualmente tão vivos quanto aqueles do texto fonte.

De todo modo, em tradução, “a teoria é a prática”, como já dizia Meschonnic (1999: 223). Motivo pelo qual, nas linhas que seguem, nos debruçamos sobre a tradução de um dos poemas de Hilda Hilst (1997) a partir das considerações acima sobre a tradução poética no contexto francês. A primeira questão é saber em que medida procedeu-se a uma tradução etnocêntrica, compreendida aqui como deformadora ou teratológica, para, em seguida, refletir sobre o projeto ético envolvido na mesma.

\section{Traduzir o poema XXXVI de da morte. odes mínimas de Hilda Hilst}

A tradução que fiz dos poemas de Hilda Hilst data de 1995 e 1996, tendo sido publicada numa coedição Brasil-Québec em 1997. No momento em que foram realizadas as traduções, eu não tinha ainda desenvolvido uma reflexão teórica sobre o 
ato de traduzir. Voltar ao texto traduzido com uma perspectiva crítica não foi tarefa fácil devido à enorme quantidade de escolhas à época que hoje seriam distintas. No conjunto, contudo, alguns poucos poemas pareceram-me resistir melhor ao tempo. Um deles é o poema "XXXVI":

$\begin{array}{ll}\begin{array}{l}\text { Um peixe lilás e malva } \\ \text { Num claro cubo } \\ \text { De sons e água. }\end{array} & \begin{array}{l}\text { Un poisson lilas et mauve } \\ \text { Dans un clair cube } \\ \text { De sons et d'eau. }\end{array} \\ \text { Assim te mostrarás. } & \text { Ainsi tu te montreras. } \\ \text { Um perfil curvo. } & \begin{array}{l}\text { Un profil courbe. } \\ \text { Soma de asas. }\end{array} \\ \text { Um quase escuro } & \begin{array}{l}\text { Somme d'ailes. } \\ \text { Sobre as vidraças. }\end{array} \\ \text { E fios e linhas } & \text { Sur les vitrages. } \\ \text { Trançando máscaras } & \\ \text { Para a minha cara: } & \text { Et fils et lignes } \\ \text { Rubra mandala } & \text { Tressant des masques } \\ \text { Para um perfil. } & \text { Pour mon visage : } \\ & \text { Rouge mandala } \\ \text { Então ajusto } & \text { Pour un profil. } \\ \text { Para o mergulho } & \text { Alors j'ajuste } \\ \text { Cores e máscara. } & \text { Pour la plongée } \\ \text { Sou eu. Um peixe rubro } & \text { Couleurs et masque. } \\ \text { E um outro lilás e malva. } & \text { E'est moi. Un poisson rouge }\end{array}$

Trata-se de um poema que reflete bem a poética hilstiana; parte-se de determinadas metáforas, no caso, o peixe e a morte, que se desdobram ao longo do texto por uma justaposição de imagens, a partir das quais discorre uma certa narratividade.

Neste caso, na primeira estrofe, surge "um peixe”; são formas e cores mais claras (lilás, malva, claro) que flutuam e ecoam. Segue-se um verso solto em que se afirma ser esta a forma que adquirirá a morte (o "tu"que atravessa todo o livro, com o qual o sujeito-enunciador dialoga e ao qual se confronta); o uso do verbo "mostrar" reforça a evidência.

O reflexo do peixe como imagem da morte adquire, nas duas estrofes seguintes, alguns novos contornos: as nadadeiras são "asas" e as escamas "mandalas”, onde se refletem cores menos claras e precisas (fios, linhas, máscaras, quase escuro) que se deslocam do lilás ao rubro. Nas estrofes finais, fundem-se no sujeito-enunciador as imagens do peixe e da morte. Após o mergulho, que se sabe mimese (máscara), 
emergem, num espelhamento do escuro ao claro, o mesmo espectro de cores; e os peixes também espelham-se, são dois: um rubro e um outro lilás e malva.

O claro-escuro do poema se adensa pela rede fono-semântica "de sons e de água” que permeia o texto e que pode ser exemplificada pelas rimas toantes no final de cada verso e pelos sons que as circundam. ${ }^{1}$

Na primeira estrofe se apresenta uma tessitura relativamente clara em "MAlva/ CUbo/ Água”. A abertura não é, contudo, total, pois além do som fechado do [u], tanto em “malva quanto em "água” ressoa a vogal [u]. O escorregadiço do som só se resolve na estrofe seguinte, em “mostraRÁS”, ápice do que se revela.

A dominância de vogais abertas torna-se menos intensa na segunda estrofe. $\mathrm{O}$ “CUbo” da primeira estrofe retumba em “CURvo/ TURvo” da segunda. Som fechado, “quase escuro”, em contraponto à sonoridade menos presente, ainda que dominante, da rima toante aberta de “Asas/MÁScara”. Essa abertura se torna mais escorregadia e aguda na terceira estrofe. Deslizam entre as "LInhas" do "PerFIL", “MÁScaras/CAra/manDAla”. É somente no momento do “aJUSte” para o “merGULHO” que surde um "peixe RUbro” mais denso e escuro. Peixe que, contudo, não deixa também de ser outro mais evidente, ainda que sempre fugidio e líquido: “LiLás e MaLVa”. A rede fonossemântica descrita acima é, sem dúvida, uma das estruturas significantes subjacentes ao texto.

Note-se ainda que o "mesmo" e o “outro" movem-se ao longo do poema num jogo de indeterminações, seja pela presença do artigo indefinido "um peixe, um claro cubo, um perfil curvo, um quase escuro”, seja pelo uso de plurais não precedidos de determinantes - “sons e águas”, “soma de asas”, “fios e linhas”, “cores, máscaras”. Os únicos artigos definidos são, na ordem do poema, “as vidraças”, “a minha cara” e “o mergulho”. O primeiro remete ao espaço que contém o peixe-morte-sujeito, lugar, a princípio, “cubo claro”; depois “vidraça” e a própria “minha cara”; enfim, o lugar mesmo do "mergulho": o poema, que é mandala e máscara.

O tecido do poema urde-se, pois, como mandala; metáfora central por sua profusão, fluidez e circularidade. Além da tensão entre o determinado e o indeterminado, a repetição lexical e o jogo com o espectro de cores é central na

\footnotetext{
${ }^{1}$ Não se trata aqui de retomar a complexa discussão sobre a motivação sonora. Para nosso fins, basta a constatação mais ou menos acordada de que alguns sons, quando motivados pelo conceito, são um fator de adensamento significante. Por exemplo, considerar o caráter mais aberto do [a] e mais fechado do [u], assim como a fluidez do [1] ou a explosão das oclusivas nos parece aceitável.
} 
construção do movimento em mandala, no qual se é, de uma só vez, o mesmo e o outro: peixe e morte e eu e peixe/ malva e rubro e rubro e malva. "Rubra mandala" e o "peixe rubro" são dois tons do mesmo vermelho, assim como o primeiro "peixe lilás e malva”, sendo o mesmo é também de “um outro lilás e malva”. Retoma-se a imagem de partida, mas desta vez mediada pela máscara-mandala da linguagem; frágil e escorregadia como o peixe, “quase escura” como pode ser a morte no mergulho (que também é superfície porque som e imagem) do poema.

Retomar a rede imagética e fonossemântica acima parece ser o pressuposto para se produzir em outra superfície, no caso a língua-cultura francesa, o pulsar do gesto hilstiano. A dinâmica do poema apóia sua respiração mais profunda na espacialidade e na pontuação. Tanto no texto de partida quanto no de chegada verifica-se, inicialmente, a presença de maiúsculas no início de cada verso, independentemente da pontuação.

A pontuação, por sua vez, resume-se praticamente ao uso do ponto final, sendo a vírgula substituída pela quebra do verso e havendo uma única vez a introdução de dois pontos, antes de uma exemplificação. Os pontos, utilizados de forma bastante convencional, coincidem com as unidades de sentido, encerrando as estrofes e concluindo algumas sentenças dentro das estrofes. A exceção são as duas últimas estrofes, que podem ser interpretadas como uma única unidade de sentido. Aí, ao invés de uma vírgula, para acentuar a presença do peixe e seu duplo, há um espaçamento, espécie de silêncio entre o mergulho rubro e sua dobra (máscara?) lilás e malva. É nessa intersecção que se encontra também o único ponto dentro de um verso. Abrupta pontuação da assertiva “sou eu”, que precede o reaparecimento do peixe e seu duplo.

Assim como no texto fonte, o espectro muda suas cores no poema traduzido. $\mathrm{O}$ vaivém de formas e cores, assim como seu continente, aí também se respondem, como em: "Un poisson lilas et mauve/ dans un clair cube" ; "Un profil courbe./ Somme d'ailes./ Un presque obscur/ Sur les vitrages.” O uso dos determinantes também coincide, salvo em "Para a minha cara" onde se lê "Pour mon visage". Surge a pergunta: valeria a pena procurar aqui um grau de "pura estranheza" e forçar a "entrada" de um artigo definido le na língua francesa?

Levando-se em conta a poética de Hilda Hilst, cujo trabalho sobre a linguagem não se situa no nível da invenção sintática, pelo menos em sua poesia, creio que o movimento que seu texto encontra-se mais nas respirações (pontuação, espaçamentos) e na tessitura fonossemântica do que numa ruptura com uma determinada convenção sintática. Este motivo levou-nos a utilizar o mesmo critério em alguns outros momentos. 
Em “de sons e água”/ “de sons et d'eau”, a repetição do "de” pode ser compreendida como a retirada de alguma fluidez do verso pela introdução de uma oclusiva. Por outro lado, pela inclusão da oclusiva, além de corresponder mais à norma (que domina também no texto em português), evita-se um hiato em francês que pode, justamente, introduzir uma cacofonia pelo fato de o hiato ser muito mais marcante em francês - em português, depois do encontro vocálico, temos “água”, duas sílabas, três vogais pronunciadas e uma oclusiva, enquanto em francês tem-se apenas o som [o].

Na segunda estrofe, “Assim te mostrarás”/ “Ainsi tu te montreras”, coloca-se a questão do acréscimo do “tu”. Essa “deformação por inclusão” explica-se pelo caráter implicitante do português, que permite a supressão do pronome sujeito, enquanto em francês a supressão é, em geral, agramatical. O mesmo ocorre em “Então ajusto”/ “Alors j'ajuste”, caso em que também se optou por não acrescentar uma camada de estranheza à poética hilstiana.

O momento em que ocorre a maior variação sintática e semântica entre os poemas é na sentença “Sou eu.”/ “C’est moi”. Seria aqui possível a escolha de "Je suis”, mas, no caso, a intransitividade é menos usual e pode causar uma impressão de incompletude e hesitação, que não parece existir no texto hilstiano. Optou-se, assim, pelo “C'est moi”. Essa forma, sem equivalente em português, é construída a partir do C'est, gramaticalmente classificado como présentatif (apresentativo), e que serve para reforçar a presença, de forma assertiva, até abrupta, no poema, de um “eu”.

Uma outra escolha talvez digna de nota é a tradução de “vidraças" por “vitrages”, onde “vitres” é mais usual. Além de a própria poética hilstiana “autorizar” tal escolha pelo uso, por exemplo, de “rubro" ao invés de "vermelho", a rede fonossemântica subjacente também orientou a escolha.

Assim como no texto de Hilda Hilst, na tradução há um processo de sonoro de abertura e fechamentos, como tensões e distensões. Na primeira estrofe do poema em francês há, contudo, um fechamento maior, devido à monotongação de "malva/água" em "mauve/ eau”, que faz do "cubo" um espaço menos claro, ainda que se leia na estrofe os termos "lilas” e “claire”. O movimento rumo à claridade é portanto mais acentuado em francês e também menos fluido devido à perda dos ditongos.

Nas duas estrofes intermediárias, onde se encontra "vitrages", a tessitura fonossemântica se assemelha ainda mais: [u], [a] e [l] produzem movimentos correspondentes. Tais movimentos distinguem-se mais no final do poema, sobretudo em torno do vocábulo “mergulho”. Em francês, pode-se optar, por exemplo, pelo termo 
“plongeon" ao invés de "plongée", escolha sonoramente mais densa e escura. Entretanto, em francês, “plongeon” remete a salto, ao movimento que precede a entrada na água, enquanto “plongée” indica o deslocar-se dentro da água. Fica o impasse: priorizar o movimento do som ou o movimento do sentido?

\section{Éticas do traduzir}

Este exemplo parece um bom ponto de partida para se discutir as propostas éticas do traduzir. Se levarmos as considerações de Berman ao "pé da letra”, a busca de uma pura estranheza levaria talvez a uma escolha pela "rede significante subjacente", entretanto, o próprio Berman afirma a existência de um “pacto draconiano”que não permite ao tradutor ir além da "textura do texto". Resta saber onde reside a textura: na iconicidade ou numa precisão vocabular significativa para a imagística do poema? A ética de Berman parece lidar mal com a questão, pois seu pressuposto é o da existência de uma ética, que acaba por tornar o traduzir aistórico. ${ }^{2}$

A postura de Meschonnic segue mais interessante. Por trabalhar com categorias mais amplas, sua sistemática da deformação não incorre no risco de prescrever demais o ato tradutório. Nesse sentido, pode-se dizer que a tradução apresentada não é deformadora, pois não se verifica no poema em francês grandes acréscimos ou omissões, nem há inversões de palavras ou de grupos de palavras, nem tampouco verifica-se não-concordâncias ou anticoncordâncias.

Além disso, sua poética do traduzir lida com o gesto tradutório em sua historicidade e sua subjetividade discursiva. Nesse sentido, pode-se compreender, por exemplo, o movimento de maior fechamento e obscuridade da estrofe inicial no poema em francês como um adensamento do jogo entre o "peixe” e seu “outro", potencializando o papel intermediário do mauve (malva).

A ética do traduzir como ética da linguagem em movimento configura-se, desse modo, como uma postura mais pertinente com a complexidade envolvida no ato tradutório. Prática que procuro compreender como gesto de um sujeito que se aproxima e que se desloca. De maneira similar ao peixe-texto de Hilda, a tradução faz-se mandala

\footnotetext{
${ }^{2}$ É sabido que Berman, em seu último livro, Pour une critique des traductions: John Donne (Gallimard, 1995) revê suas posições e propõe uma outra analítica do traduzir, menos negativa do que aquela de $A$ tradução e a letra; o que não impede Berman de continuar considerando em seu livro de 1995 a "manipulação do original” uma atitude "desrespeitosa” (p.93) e, portanto, de acordo com seus princípios, "antiética”.
} 
cujos múltiplos feixes colorem e faíscam, escapam e se fixam, num mesmo e num outro lilás, malva e rubro e redivivo.

\section{Referências}

BERMAN, Antoine (2007 [1985]) A tradução e a letra ou o albergue do longínquo. Tradução de Marie Helène-Torres, Mauri Furlan e Andréia Guerini. Rio de Janeiro: 7letras.

HILST, Hilda (1997) de la mort. odes minimes. Tradução de Álvaro Faleiros. São Paulo/Montreal: Nankin/Noroît.

MESCHONNIC, Henri (1973) Pour la poétique II. Paris: Gallimard. . (1999) Poétique du traduire. Paris: Verdier. . (2007) Éthique et politique du traduire. Paris: Verdier. 